\title{
Environmental Management within Projects
}

\author{
Ying $\mathrm{He}$ \\ School of Management Science and Engineering, AHUT \\ Ma'anshan 243002, Anhui, China \\ E-mail: 520fruit@163.com
}

\begin{abstract}
The role of environmental management within projects is playing a more and more essential part to the firms and public. Because of the benefit of implementing environmental management, different methods are being used to improve environmental management in projects especially in industry. However, the application of these methods leads to an increase in labor use, materials costs and other costs, which can limit their implementation. This paper provides the benefits and the barriers to the implementation of environmental management within projects, and some effect ways to improve it. It should help stakeholders to adjust their environmental management policy by efficient resources distribution within their firms.
\end{abstract}

Keywords: Environmental Manangement, Global coorperation, Environmental pollution, Recycle

\section{Introduction}

In the modern world, making a high-quality project is playing a more and more essential part in the competitive life. There is no doubt that an initial blueprint of project management in the process of making a perfect project is very significant. Nevertheless, the environmental management is also doing a critical role in this course of action.

During the last few years, the consciousness of people for the protection of environment in the general public has been gradually increasing. Various kinds of pressure groups are acting in defense of the environment. The governments are also promoting more and more set of laws to protect the environment and the community in general (Chakrabarti and Mitra, 2004, pp 53-66). Environmental management has incessantly grown in importance over the last 2 decades not only in terms of the worldwide environmental market, but also as a driver of advances in the entire area of projects. The growth of pioneering environmental management is also the key factor towards the objective of developing a new sustainable project management (Centi et al. 2002, pp 3-15).

\section{The Benefits of Implementing Environmental Management within Projects}

Environmental protection has come a long way in the last 40 years. In the sixties and seventies of the last century it began with grudging application of technologies to clear out pollution caused by operation of plants, use of products and discarding of wastes. That technology has evolved from easy equipment based on simple principles to often complex equipment using the latest information in a variety of fields of engineering. Soon it became clear that prevention of pollution was much more useful and economically sound. This influenced the way the technology was used, from end of pipe to integrated solutions focusing on prevention. New technology and new optimization techniques have been developed. Over the last 20 years awareness has grown that pollution as such is not the major issue but just one of the side effects of wasting the resources we need for a sound and sustainable economy (Venselaar 2005, pp 58-65). From what have been mentioned above, we can see very easy that the environmental management within projects has become more and more important in our daily life. However, why it becomes so essential? We can get the answers from the benefits of implementing environmental management within projects.

From the last century, many firms have undergone rapid changes since adoption of the reform as well as the global cooperation. Nevertheless, meanwhile, these firms has paid a great cost for its rapid development: severe environmental deterioration including overexploitation of ground water, generation of solid and industrial wastes, obliteration of the ecosystem, and other problems related to land, water, and atmosphere. Especially in the construction industrial in which has undergone great changes due to rapid industrialization and urbanization during the past decades (Zeng et al. 2005, pp 645-656). Pollution been brought about by construction activities has become a serious problem. Pollution and risks do not only irritate residents nearby, but also affect the health and well-being of people in the entire urban.

There are noticeable benefits to the companies from putting environmental management into practice of project management, such as reducing the production of wastes, and decreasing the use of materials and techniques that could have hurtful effects on the environment. The benefits to the owners of these firms can be in a number of ways, for 
instance, cost savings due to the reduction of fines connected with confidences as a result of going along with environmental legislation (Shen and Tam, 2002, pp 535-543).

Newman and Breeden(1992 cited Scanlon 2007, pp 711-723) imply that the acceptance of an environmental management program by a company would have the following benefits, just like a competitive advantage for green marketing as a reply to consumer expectations, media recognition of environmental efforts, the minimization of risks and future costs and positive recognition of environmental efforts by stakeholders.

\section{The Barriers of Implementing Environmental Management within Projects}

The environment is a term used to give explanation about a number of factors and relevant factors of a firm's environment which have an effect on the design of the project manager as well as the importance of pursuing benefits, technology and innovation, environment change, competition behavior, price competition and the number of different project managers faced by the level of barriers (Löfsten and Lindelöf, 2005, pp 725-738). From what has been mentioned above, we can see that implementing the environmental management is not an easy way to go. Getting a successful environmental management we must clean off many barriers.

Even though economic growth and environmental protection are not necessarily reciprocally exclusive pursuits (Kuntz-Duriseti,2004, pp 291-301), critics of the necessary of implementing environmental management still exist. Strengthen the knowledge of environment, when characterized as protecting the environment at all costs, may be infeasible, especially when there is demand for limited resources for more practical, creative and/or higher priority investments, including addressing other environmental troubles.

It seems that there is a certain level of bitterness to the full implementation of environmental management in projects especially in construction, and barriers exist both internally and externally (Shen and Tam, 2002, pp 535-543). For instance, increase in management costs, lack of trained staff, time-consuming for improving environmental performance and so on.

Ever increasing utilization is putting a strain on the environment, polluting the Earth and destroying ecosystems. Large-scale economic development in the developed countries occurring in the first half of the last century has left deep symbols on the accessibility and quality of natural resources. These are dangerous side-effects of the developing countries which will follow the named successful way. Changing the idea of being winning and reinforcing the environmental management with projects has been a common feature of most countries' firms in recent decades. As nations develop and their economies grow, so too does the pollution of environment. For instance, developing Asian countries have shown a steady growth in both population and in economic activity. In addition, the pollution of environment may not only be the result of too many firms competing over a limited market base but also some project managers utilizing environment extremely and abusively to the detriment of other sectors of society, poorer nations, future generations and other species (Hubacek et al. 2007, pp 1084-1096).

As we know, the industry is a project which makes the main contribution to environmental pollution (Shen and Tam 2002, pp 535-543). As a leader of such a industrial project, the project manager's consciousness plays an essential part in the process of implementing environmental management in a project. However, in general, these project managers do not seem to consider that the implementation of environmental management will bring cost savings. A large number of project managers' interviews suggested that there is a net cost increase in implementing environmental management as a consequence of the investment in equipment, staff training, human resources and technology such as water treatment and the application of noise-barrier materials. Industrial project managers' practice demonstrates that the cost of implementing environmental management is far more than the worth of the cost savings speculated (Shen and Tam 2002) which are very harmful for implementing environmental management in the project.

From a recent report (Chopra et al. 2001, pp 67-75), I get an information that nearly $71 \%$ of the people surveyed in one country have no knowledge about environmental management issues. The low level of consciousness regarding the environmental impacts of inappropriate management of environmental makes it difficult to implement environmental management in projects especially in industry. In putting the method to implement environmental management just like recycling and disposal programs into practice, cooperation between both the public and the private sectors is required to make sure the success of the environmental management program.

As can be seen from the description above, we can get a fact that the firms stated that the problem they typically came across while implementing the environmental management practices is lack of environmental awareness in all the areas including in the employees, suppliers and customers (Yüksel, 2008, pp 50-57). As a consequence of society does not have sufficient awareness, firms face many troubles in collecting the components to be recycled. If environmental awareness in the society increases, the success of the environmental plans is expected to rise. The firms also stated that they encountered with many troubles on account of the employees lack of education and awareness on environmental issues. For this reason, the practices for increasing the environmental awareness of the employees are those that the firms mostly concentrate on while implementing environmental programs. The fact that firms consider environmental 
issues as cost drivers was explained in previous depiction. In this analysis, the firms stated the same trouble that environmental practices bring considerable costs. As well as these, the firms face challenges in the practices of dealing with pollution and complying with the laws. The support and incentive of the government on environmental issues may assist the firms to minimize these. In addition, customers have very important roles in the success of the environmental management implementation.

What is more, financial restrictions, increase in transport costs, improper location of landfills, shortage in industrial and bulk waste separation, the limited availability of trained and skilled personnel, and the low consciousness level regarding health and environmental impacts can slow the establishment and implementation of environmental management.

\section{Finding an Effective Way to Improve Environmental Management in Projects}

In the competitive world, the firms want to get much more benefits must pay for much more efforts than before. The number of factories in this world is increasing every year in company with production with the purpose of fulfill the market demand and to take advantage of opportunities to export to the other factories. The focal point of industry is on the number and quantity of products, but industrial waste production during the withdrawal of resources, production processes and use by consumers has been by no means considered in the overall manufacturing design which could cause serious environmental risks to the air, water and soil of the world (Mrayyan and Hamdi, 2006, pp 195-205). From what have been mentioned above, we can have a conclusion that finding an effective way to improve environmental performance in projects especially in industry is very important.

Recycling is an effective way which can reduce the pollution and produce beneficial materials. This method represents a significant way of dealing with the pollution with a high potential for future development. Recycling is growing all over the world, encouraged by the economic and environmental benefits it brings. The manufacturers can use recyclable materials which are mainly paper and cardboard. Manufacturers must be encouraged to recycle part of their industrial products though the successful implementation of recycling faces many difficulties such as low levels of consciousness and the lack of appropriate funding. Recycling can be supported by encouraging separation at the source. The best method of waste separation at the source can be stimulated by financial incentives, legislation and the raising of environmental awareness (Mrayyan and Hamdi, 2006, pp 195-205).

From a recent report we can see that in this first stage of the 21 st century, all corporations must thoroughly understand how social pressures are affecting their markets as well as become accustomed accordingly. The pressure to evidence corporate social liability is causing companies to place increasing demands on manufacturers to be accountable for the full life-cycle of the products they manufacture (Hawken et al. 2000 cited Scanlon, 2007, pp 711-723).

From a research by Johnstone et al. (2004, pp 685-707) I know that the most important factors of making the firms adopt the environmental plan were government regulations, neighborhood/community groups and customers. The sales-to-asset ratio had a negative sign, but was not mainly important. What makes me surprising is that the firm size was not important. As what have been discussed above, I can see that the government must do something in implementing the environmental management. In order to deal with the environmental problems, the government should act out laws on environment protection such as the ratification of Environment Protection Act, Water Pollution Protection Act, Air Pollution Protection Act, Solid Wastage Pollution Protection Act and Noise Pollution Protection Act. Those regulations will provide guidelines for those practitioners to tighten up environmental protection (Zeng et al,. 2005, pp 645-656).

In the organization of project management, the effective way to leads much better environmental performance relies on the utilization of knowledge. As a result that many small actions and decisions that all parts of this organization can make in their everyday work can cumulate to large improvements in the environmental impacts of the organization. Employees should be brought to understand how they may contribute to the efforts for sustainability authorized by the organization. Without their ingenuity and expertise, the environmental management and sustainability proposals of an organization may be limited to a number of technical improvements and pass over large efficiency gains initiated by the work force. Cohen-Rosenthal and Hale (2000 cited Perron et al,. 2006, pp 551-562) make an appoint that an effective way for improved environmental performance requires that all employees in an organization have knowledge of the natural systems and their functioning in addition to understand their effect on project performance. This understanding allows the employees to take part in the environmental management effort, and helps develop environmental performance of the company.

Two recognized ways to manage uncertainty effectively in environmental decision making: safe minimum standards (SMS) that seek to keep away from worst case scenarios and an expectations approach that averages across possible outcomes. Taken together, the SMS and expectations approach place upper and lower bounds on a precautionary rule response. On the other hand, both of these methods are suboptimal from a welfare perspective, which is a significant consideration for policymakers. The SMS approach leads to policy advices that may be too precautionary from a 
cost-benefit point of view, while the expectations way does not adequately address the welfare costs uncertainty itself imposes.

The promotion of environmental management and the assignment of sustainable development have given rise to pressure demanding the adoption of proper ways to improve environmental presentation across all projects including industry. Industry is not an environmentally friendly activity naturally. Existing research puts forward that industrial activity is a main contributor to environmental pollution (Shen and Tam, 2002, pp 535-543). As a result, we must put the most of our efforts in industry.

In following the mission of sustainable development, efforts towards practicing environmental management in the projects concluding industry have been growing rapidly. The environmental management system (EMS) is built as a tool based on this trend. An Environment Management System (EMS) is a tool for managing the impacts of a project management's activities on the environment. It provides a structured approach to planning and implementing environment protection measures. The EMS defined in the standard ISO 14000 is promoted as a vehicle for organizations to develop environmentally friendly performances. The system provides a standard structure that includes environmental policy, planning, completion and operation, checking and corrective action, and measurement review and development. It was developed to support project managements to improve their environmental management on a voluntary basis through logical allocation of resources, assignment of responsibilities, and continuing assessment of practice (Anon. 2007). An EMS is a structured method to managing the environmental effects of a group's operations and a positive tool for communicating the value of an environmental program to a broad variety of audiences. A complete EMS contains defining specific environmental indicators that can be tracked and regularly assessed to decide whether operations change to become more environmental friendly. The acceptance of an EMS as a framework for integrating company environmental protection programs and practices is growing among both domestic and multinational companies around the world. Hui et al. (2001 cited Argandoña 2004, pp 41-52) suggested that implementing the EMS provided an useful guidance for companies to concurrently establish, develop and review their business practices towards both corporate and environmental targets.

From what have been discussed in Hawken's et al. (2000, pp 87-90) article, we can see that in this first stage of the 21st century, all companies must thoroughly recognize how social pressures are affecting their markets and adapt accordingly. The stress to evidence corporate social responsibility is causing companies to place increasing demands on their project management to be accountable for the full life-cycle of the products they product. A project manager in environmental management is seen as a driving part in the success of implementing environmental management programs. From this we can get a conclusion that the corporate leadership - project manager's consciousness is also an essential part in the process of improving environmental management.

The consciousness and eagerness to improve industrial environmental performance depends on many different factors. Generally speaking, the higher the external stresses, the higher will be the commitment of any company leader. As bigger companies attract more attention, are more uncovered to external pressures and have a bigger impact they will naturally become more conscious and be more eager to improve their environmental performance. For this purpose, they will also allocate more resources than smaller companies. From a recent survey (Hicks and Dietmar, 2007, pp 395-408) we can know that large companies are demonstrating an increasing willingness to address environmental and social responsibility issues. It should be made a note of the survey that despite the restrictions of the survey, those companies involved must be considered to be the forerunners or "early adopters" that will set the performance standards for later followers. As a result, similar to environmental monitoring standards are of limited use if companies are incapable of meeting their criteria. In addition, unlike larger companies, small companies without a position in an international supply chain or division of labor are under less external pressures to improve their environmental performance. In general, raising the large company's awareness of improving environmental management in projects is bearing the brunt of all the activities.

\section{Conclusions}

The connection of results obtained from this paper has highlighted the fact that key barriers and drivers change on a national basis, owing to local circumstances, such as waste disposal costs, raw material costs, legislation and stakeholders' awareness and so on. The fact that these key barriers and drivers also differ on a part basis also highlights the current mistake by current research (Burke and Gaughran, 2006, pp 566-575). However, we still can get the sustained key drivers and barriers from these uncertainties. As a result, the majority of current research should focus on the benefit of implementing environmental management, the barriers about it and the effect ways to deal with it.

This paper observes the importance of various benefits, barriers and measures from and for implementing environmental management in projects within the industry. The results of the analysis point out that contribution to environmental protection, reduction of environmental risk, improving environmental management and cost saving due to the reduction of environment-related convictions were considered the most significant benefits of implementing environmental management in projects especially in industry. On the other hand, the existence of barriers for 
implementing environmental management has been established, and major barriers include increasing management cost, lack of trained staff and expertise, lack of sub-contractor cooperation, lack of stakeholder awareness and time-consuming for improving environmental performance and so on. At last, it gives some ways to implement the environmental management.

As we know that a majority of firms is competing in a reality of limited resources and interlinked ecological systems. The implementation of environmental management methods requires that the values and culture of the company must permeate the activities of the organization and be adopted by all personnel. The implementation of environmental management systems or other forms of responsible environmental management require some level of change in the companies' values and culture to permeate the organizations' behaviors. These systems and this change in culture require a useful and sustained education and awareness effort to ensure that the information necessary for environmental management is acquired and retained, or the benefits of implementing environmental management will most probably not be realized (Power et al.2004, pp 37- 42).

When a firm realizes that its main stakeholders use their power to influence its environmental management practices, it tends to adopt an explicit mode of environmental management (Céspedes-Lorente et al.2003, pp 333-358). Hence, my investigation suggests that improving the stakeholder's awareness of environmental management is very essential. There is no doubt that much work remains to be done if we are to recognize how to improve environmental management in projects.

\section{References}

Anon. (2007). Environmental Management Systems(EMS). Poole: Australian Government. [Online] Available: http://www.environment.gov.au/settlements/industry/corporate/ems.html [Accessed February 24, 2009]

Argandoña, A. (2004). On Ethical, Social and Environmental Management Systems. Journal of Business Ethics. Pp. 41-52.

Burke, S., and Gaughran, W.F. (2006). Intelligent environmental management for SMEs in manufacturing. Robotics and Computer-Integrated Manufacturing, pp. 566-575.

Centi, G.; Ciambelli, P.; Perathoner, S., and Russo, P. (2002). Environmental catalysis: trends and outlook. Catalysis Today. pp 3-15.

Céspedes-Lorente, J., Burgos-Jiménez, J.D., and Álvarez-Gil, M.J. (2003). Stakeholders' environmental influence. An empirical analysis in the Spanish hotel industry. Scandinavian Journal of Management. pp. 333-358.

Chakrabarti, S., and Mitra, N. (2005). Economic and environmental impacts of pollution control regulation on small industries: a case study. Ecological Economics. pp 53-66.

Chopra, M.; Reinhart, D., and Wail Abu-Al-Shaar, D. (2001). Jordan Municipal Solid Waste Management Collaborative Research. Wilson Boulevard. pp 67-75.

Hawken, A. L., and Lovins, H. L. (2000). Natural Capitalism. Little Brown\&Company. pp. 87-90.

Hicks, C., and Dietmar, R. (2007). Improving cleaner production through the application of environmental management tools in China. Journal of Cleaner Production. pp. 395-408.

Hubacek, K., Guan, D., and Barua, A. (2007). Changing lifestyles and consumption patterns in developing countries: $A$ scenario analysis for China and India. Futures. pp. 1084-1096.

Johnstone, N., Scapecchi, P., Ytterhus, B., and Wolff, R. (2004). The firm, environmental management and environmental measures: lessons from a survey of European manufacturing firms. Journal of Environmental Planning and Management. pp. 685-707.

Kuntz-Duriseti, K. (2004). Evaluating the economic value of the precautionary principle: using cost benefit analysis to place a value on precaution. Environmental Science\&Policy. pp. 291-301.

Löfsten, H., and Lindelöf, P. (2005). Environmental hostility, strategic orientation and the importance of management accounting - an empirical analysis of new technology-based firms. Technovation. pp. 725-738.

Mrayyan, B., and Hamdi, M. R. (2006). Management approaches to integrated solid waste in industrialized zones in Jordan: A case of Zarqa City. Waste Management. pp. 195-205

Perron, G.M., Côté, R. P., and Duffy, J. F. (2006). Improving environmental awareness training in business. Journal of Cleaner Production. pp. 551-562.

Power, M., Bonifazi, C., and Desouza, K.C. (2004). The ten outsourcing traps to avoid. Journal of Business Strategy. pp. 37- 42. 
Scanlon, N. L. (2007). An analysis and assessment of environmental operating practices in hotel and resort properties. International Journal of Hospitality Management. pp. 711-723.

Shen, L.Y., and Tam, V.W.Y. (2002). Implementation of environmental management in the Hong Kong construction industry. International Journal of Project Management. pp. 535-543.

Venselaar, J. (2005). Environmental production: A shifting focus. Process Safety and Environmental Protection. pp. 58-65.

Yüksel, H. (2008). An empirical evaluation of cleaner production practices in Turkey. Journal of Cleaner Production. pp. 50-57.

Zeng, S. X.; Tam, C. M.; Tam, V. W. Y., and Deng, Z. M. (2005). Towards implementation of ISO14001 environmental management systems in selected industries in China. Journal of Cleaner Production. pp. 645-656. 